Marquette University

e-Publications@Marquette

Nursing Faculty Research and Publications

Nursing, College of

$11-1-2008$

\title{
Coping Difficulties After Hospitalization
}

Judith Fitzgerald Miller

Missouri Sinclair School of Nursing

Linda Piacentine

Marquette University, linda.piacentine@marquette.edu

Marianne Weiss

Marquette University, marianne.weiss@marquette.edu

Accepted version. Clinical Nursing Research, Vol. 17, No. 4 (November 2008): 278-296. DOI. (C) SAGE Publications 2008. Used with permission. 


\title{
Coping Difficulties After Hospitalization
}

\author{
Authors: Judith Fitzgerald Miller, Linda B. Piacentine, \& Marianne Weiss
}

\begin{abstract}
Coping difficulties of 113 adults 3 weeks after hospital discharge were identified using the Post-Discharge Coping Difficulty Scale and a brief focused telephone interview (11item guide). Overall, low difficulty scores were reported $(M=23.9, S D=18.2$, range $=0$ to 100). Qualitative data reveal specific coping difficulties in the categories of stressors, specific difficulties, caring for self, managing the condition, family, advice needed, contact with the health care system, and what they wished they knew before discharge. A core theme of biographical reconstruction emerged.
\end{abstract}

Hospitals are no longer places for patients to stay for recovery and convalescence. Care received within the hospital is directed toward managing the acute episode; patients are then discharged as soon as possible and at times in haste to care for themselves at home. Indicators of readiness for discharge from the hospital are primarily determined by the medical staff usually evaluating physiologic parameters but seldom including perspectives of the patient (Weiss et al., 2007). In addition to the patient's physiologic stability and health care provider judgment, hospital discharge has been based on system constraints and managed care directives with the focus of patient centeredness missing (Anthony \& Hudson-Barr, 2004). Discharged at an intermediate stage of recovery (Korttila, 1991), patients return home to manage their new or changing medical condition as well as their personal and family life. The recovery process is unfamiliar for many with the unexpected stressors for which they feel inadequately prepared and which result in difficulty managing posthospitalization care (Bull \& Jervis, 1997). These new stressors occur at a time when their coping residual is compromised because of illness, surgery, and/or fatigue.

\section{Problem}

New stressors confront patients in the early days after discharge from the hospital. It is at this time that early signs of impending problems need to be detected and complications avoided. Patients must be astute in self-monitoring and self-management to avert posthospitalization crises. Nurses need to understand patients' experiences with coping difficulties, stressors, self-management demands, and challenges perceived by family members to adequately prepare their patients for this transition from hospital to home. Little is known 1 Miller, Piacentine, \& Weiss 
about patients' specific stressors and needs during the initial weeks after hospital discharge in this era of shortened lengths of hospital stay. Patients' perspectives on care demands during the immediate weeks after hospital discharge need to be discovered so that nurses can anticipate these demands, understand patients' interpretations about care directives, and more thoroughly prepare patients to successfully confront potential challenges when they are alone at home. In addition, readmissions, emergency department (ED) visits and unnecessary contacts with health care providers can be prevented.

\section{Background}

The American Hospital Association and the Picker Institute (1997) discovered in their study of 23,763 patients discharged from hospitals that $29 \%$ were dissatisfied with their preparation for discharge, had difficulty obtaining information needed to adequately care for themselves, and felt a sense of "abandonment" after they were discharged. Of those who were dissatisfied, $30 \%$ were not informed about "danger signals" to watch for, medication side effects had not been reviewed with $31 \%$, and $37 \%$ did not know when they could resume normal activity. Information needs for successful postoperative self-care management have been identified for people after discharge and include information about diet, mediations, pain management, functional activities, wound care, and self-monitoring for potential complications; in addition, patients report handling worries about the expected course of recovery, managing equipment, and appropriate indications and timing for communicating with health care professionals and accessing care services (Anthony \& Hudson-Barr, 2004; Bull \& Jervis, 1997). Fewer needs were identified prior to admission (4.74) and just prior to hospital discharge (5.05) compared to after discharge home (5.35) (Anthony \& Hudson-Barr, 2004), suggesting that patients may not anticipate the complex and unexpected realities of the posthospitalization period (LeClerc, Wells, Craig, \& Wilson, 2002).

Corser (2006) classified postdischarge needs as competent self-care decision making, service coordination, physical care, and social functioning. Elderly women after hospital discharge described their preparation for self-care as "falling short of the mark" (LeClerc et al., 2002). Basic physical needs were met, but preparation for discharge was "reductionistic" and did not involve the women in planning and decision making. With a need for efficiency, nurses may review discharge instructions with patients without adequate inclusion of the patients' perspectives (Bull, Hansen, \& Gross, 2000), and often these discharge instructions are standardized and in writing. Considerations of person-centered care and health literacy with an 2 Miller, Piacentine, \& Weiss 
eye on desired outcomes may not be the nurses' focus.

People who live alone pose unique challenges in the transition from hospital to home. Social isolation has increasingly been found to be a psychosocial risk factor in illness (Friedmann et al., 2006; Rozanski, Blumenthal, \& Kaplan, 1999). One demographic proxy measure used for social support is living alone (Frasure-Smith et al., 2000). Living alone may lead to increased morbidity and mortality and increased use of outpatient services (Guzman, Sohn, \& Harada, 2004) or admission to a nursing home for the elderly after a medical illness and discharge to the home (Mahoney, Eisner, Havighurst, Gray, \& Palta, 2000). Not living alone may improve survival rates for COPD patients (Crockett, Cranston, Moss, \& Alpers, 2002). Living alone was found to be associated with lower scores on the Readiness for Hospital Discharge Scale among hospitalized adult medical-surgical patients (Weiss et al., 2007).

Wagner and colleagues (2005) summarized the steps in successful preparation of patients for self-management to include (a) assessing patient competence, attitudes, and goals; (b) providing advice about care founded on evidence; (c) assisting the patient with developing realistic goals; (d) identifying barriers and strategies to achieve the goals; and (e) arranging for additional resources and support as needed. In a randomized controlled trial of 223 heart failure patients, those who received intensive discharge transition preparation and support that included a 1-hr one-on-one teaching session and telephone follow-up at 30, 90, and 180 days had significantly fewer days hospitalized and significantly fewer deaths than the control group that received standardized discharge care. The cost savings were $\$ 2,823$ for each person in the experimental group (Koelling, Johnson, Cody, \& Aaronson, 2005). In a randomized controlled study of 712 chronically ill elders, people assigned to the experimental group who were prepared for hospital discharge by receiving a "transition coach" and encouragement to take an active role in their care and by expressing personal preferences for discharge plans had significantly fewer rehospitalizations at 30, 90, and 180 days than did the people in the control group who received routine care (Coleman, Parry, Chalmers, \& Min, 2006). Patient centeredness in discharge preparation was key to successful discharge transitioning to homebased self-care in these studies.

\section{Framework}

Meleis's transition theory (Meleis et al., 2000) provided the theoretical framework for the parent study of predictors and outcomes of readiness for hospital discharge from which the data for this analysis were derived (Weiss et al., 2007). For this analysis, a model of patient-centered 3 Miller, Piacentine, \& Weiss 
care provided an interpretive framework. Patient-centered care is defined as care that is "respectful of and responsive to individual patients' preferences, needs, and values and ensures that patient values guide all clinical decisions" (Institute of Medicine, 2001, p. 6). Arriving at mutual decision making is dependent on a trusting relationship between the patient and health care provider. Patients not only need to have adequate information about care options but also need the opportunity to express beliefs and goals (Lauver et al., 2002) and fully participate in care decisions. A shift from traditional power held solely by the health provider to sharing it with the patient occurs in patient-centered care. Emphasis is on the patient's perspective, selfdetermination, independence, and decisional choice in health-related matters (Cumbie, Conley, \& Burman, 2004). This involves barrier identification, self-monitoring, and patient empowerment. Bezold (2005) described seven dimensions of patient-centered care: (a) respect for patient's values, preferences, and expressed needs; (b) coordination and integration of care; (c) information, communication, and education; (d) physical comfort; (e) emotional comfort; (f) involvement of family and friends; and $(\mathrm{g})$ transition and continuity through phases of care. Integrating concepts of patient-centered care in preparing for hospital discharge may affect the success of this transition from hospital to home.

\section{Purpose}

The purpose of this study is to determine the nature of coping difficulties during the first 3 weeks after hospital discharge by adults with medical-surgical conditions. Specific research questions include the following:

1 What is the level of coping difficulty reported on the Post-Discharge Coping Difficulty Scale (PDCDS) by patients 3 weeks after hospital discharge?

2 Are there differences in postdischarge coping and frequency of accessing the health care system (calls to the health provider, calls to the hospital, unscheduled office visits, urgent care or ED visits, readmission) within the first 3 weeks after discharge by living status (living alone and not living alone)?

3 What specific coping difficulties do patients with high and low coping difficulty scores identify in the 3 weeks after hospital discharge?

\section{Design}

4 Miller, Piacentine, \& Weiss 
This descriptive, cross-sectional study is a component of a larger study of adult medicalsurgical patients' "Perceived Readiness for Hospital Discharge" (Weiss et al., 2007). Qualitative and quantitative data on post-discharge coping difficulty were collected during a brief telephone interview that was administered 3 weeks after hospital discharge.

\section{Sample}

The convenience sample consisted of 147 adults 18 years of age or older who were hospitalized on medical or surgical nursing units of a Midwestern urban tertiary medical center and whose discharge destination was their home. Only English-speaking patients were included. Patients discharged home with hospice care and patients who were unable to consent because of cognitive incapacities were excluded. Respondents were required to have telephone access for the postdischarge contact. Of those who enrolled in the study while in the hospital, 113 respondents completed the postdischarge phase of the study (2 patients died and 32 were unavailable for the telephone interviews) and compose the sample for this analysis. The sample size was determined for the larger study (Weiss et al., 2007) based on 80\% power in a multiple regression analysis with 10 predictor variables and a moderate effect size.

The mean age was 54.6 years $(S D=4.8) ; 30 \%$ were Black and $68 \%$ were White. In addition, $52 \%$ were female and $21 \%(n=23)$ lived alone. In all, $51 \%$ were surgical patients, and $49 \%$ medical patients. This was the first hospitalization for only $10 \%(n=11)$ of the sample. The Hollingshead Four Factor Index of Social Status was used to determine socioeconomic status (Hollingshead, 1975). The mean score was 39.0 (range $=3$ to 63) out of a possible 66, with a high score indicating high socioeconomic status. Sample characteristics are summarized in Table 1.

\section{Method}

\section{Instruments}

The PDCDS (Weiss \& Piacentine, 2006) was developed and tested as a measure of patient coping at home in the postdischarge period with a broad sample of patients discharged from acute care facilities. The sample consisted of adult medical-surgical patients included in this analysis as well as parents of hospitalized children and postpartum mothers. The 10-item instrument uses an 11-point response format from 0 to 10, with anchor words of not at all and a great deal or extremely at the 0 and 10 poles, respectively. The range of possible scores is 0 to 100. A high score indicates greater coping difficulty. Items in the PDCDS measure difficulties 5 Miller, Piacentine, \& Weiss 
with stress, recovery, self-care, self-medical management abilities, family difficulty, help and emotional support needed, confidence in self-care, and medical management abilities and adjustment (Weiss \& Piacentine, 2006). Exemplar items include, "Since you have been home from the hospital, how stressful has your life been?" and "How much difficulty have you had with your recovery?" Exploratory factor analysis of the PDCDS indicated that a single dominant factor accounted for $39 \%$ of the variance. Cronbach's alpha for the adult medical-surgical patients was .87 (Weiss \& Piacentine, 2006).

Following 5 of the 10 quantitative items on the PDCDS, respondents were asked qualitative probes to clarify and expand the meaning of the quantitative responses: (a) "Since you have been home from the hospital what has been stressful?" (b) "In terms of your recovery, what has been difficult about your recovery?" (c) "In terms of caring for yourself, what has been difficult?" (d) "In terms of managing your medical condition, what has been difficult?" and (e) "What has been difficult for your family members or close friends?" Additional narrative response questions included in the interview requested information about what advice or support was needed, reasons for calls or visits to physician offices or clinics, reasons for visits to urgent care departments or EDs, and reasons for readmissions. A final question asked, "What do you know now that you would liked to have known before your discharge?"

Accessing health care providers was included as a surrogate measure of coping difficulty. Occurrences of calls to the provider, unscheduled office visits, calls to the hospital, urgent care or ED visits, and readmission were considered to be indicators of unsuccessful postdischarge home management by the patient and family. These variables were captured by patient report during the postdischarge telephone interview. Living status was measured as living alone or living with others and was reported by the patient on a study enrollment form.

\section{Procedure}

The study was approved by university and medical center institutional review boards. Informed consent including consent to be contacted by phone 3 weeks after hospital discharge was obtained at the time of enrollment while the respondents were still hospitalized. Research assistants were trained in telephone interviewing, role-played varied responses, and learned to record verbatim the verbal responses. The research assistants called all participants $(N=147)$ beginning at 3 weeks postdischarge to conduct the telephone interviews. Attempts to contact continued for 2 weeks from the initial calls.

\section{Data Analysis}

For Research Question 1, PDCDS mean score and item mean scores were computed.

\section{Miller, Piacentine, \& Weiss}


In the analyses for Research Question 2, living status, either alone or with others, was the independent variable. An independent $t$ test was computed for PDCDS as the dependent variable. Chi-square analyses were used to determine differences in occurrences of accessing the health care system. For Research Question 3, qualitative data were transcribed verbatim. Two independent reviewers categorized the qualitative data for the PDCDS probe questions and the other narrative response questions and arrived at consensus. Themes emerged using verbatim comments from the respondents. To explore the frequencies and types of difficulties reported in people with lower and higher degrees of postdischarge coping difficulty on the quantitative measure, high- and low-difficulty groups were created by dividing the sample at the median score of the PDCDS ( $M d n=21$ ), resulting in 56 people in the high-coping-difficulty group and 57 in the low group. Qualitative responses in each category of high and low coping difficulty were described, and frequencies of responses were reported. Because the focus of the interview was on post-discharge coping difficulty, respondents had the option of indicating no difficulty as well as multiple difficulties for each question. For the purposes of the analysis, the number of respondents identifying each thematic content area were tabulated.

\section{Findings-Quantitative PDCDS Scores}

The mean PDCDS score was 23.9 (SD =18.2), with scores ranging from 0 to 80 out of a possible score of 100 . This score indicates an overall low level of posthospital coping difficulty. Item mean scores are displayed in Table 2. The item with the highest mean score was "How stressful has your life been?" (4.0, possible range $=0$ to 10). Other items indicating aboveaverage coping difficulty were as follows: difficulty with recovery (3.4), emotional support needed (3.4), and difficult for family members (2.8). Items with low scores were as follows: difficulty with self-care (1.9), managing the medical condition (1.8), and ability to care for medical needs such as medications and treatments (0.9).

\section{Living Alone, PDCDS, and Accessing the Health Care System}

Because living alone may present extra burdens for patients, coping difficulty scores of 23 respondents who lived alone were compared to the scores for 90 respondents who were not living alone using an independent $t$ test. The mean PDCDS score of people living alone was $22.3(S D=20.7)$ compared to $24.3(S D=17.7)$ for respondents not living alone; the difference was not statistically significant, $t(110)=0.47, p=.64$. Those who lived alone did not access the health system more frequently through calls to their health care provider, $\chi^{2}(1, n=111)=1.21$, 7 Miller, Piacentine, \& Weiss 
$p=.27$, calls to the hospital, $\chi^{2}(1, n=111)=1.12, p=.20$, unscheduled provider visits, $\chi^{2}(1, n$ $=112)=0.58, p=.81$, urgent or ED visits, $\chi^{2}(1, n=111)=1.03, p=.31$, or readmission, $\chi^{2}(1$, $n=102)=0.62, p=.43$, than did those not living alone.

\section{Findings-Qualitative}

\section{Coping Difficulties-Specific Stressors}

Specific stressors identified were compared in people in the high- and low-difficulty groups by dividing them at the median score of 21 on the PDCDS. The most frequent stressor identified by patients was pain or pain management ( $n=10$ in high- and $n=4$ in low-copingdifficulty categories). Managing complications and recovery challenges were the next most frequently mentioned difficulty ( $n=9$ in the high-difficulty group and $n=4$ in the low-difficulty group). Fever, infection, phlebitis, "staples opening up," and other complications were stressors for both high- and low-difficulty groups. Concern was expressed about getting back to work, being able to handle work demands, getting behind at work, and justifying being off from work ( $n$ $=9$ in the high-difficulty group and $n=5$ in the low-difficulty group). Work was important not only for role reintegration as being normal but also from a livelihood perspective. Family care was a concern for the high-difficulty group but was not mentioned by people in the low-difficulty group. Mobility issues related to inability to climb stairs, being "homebound," and getting in and out of bed were mentioned by 8 of the high-difficulty and 3 of the low-difficulty respondents. Having a changed perception of being normal and striving to resume normalcy in one's life were disclosed by 12 respondents ( $n=6$ in each difficulty group; see Table 3 ). These comments suggest that there was a disturbance in the patients' previous perceptions of themselves as being intact, having control, managing time lines, and being confident regarding resuming valued roles such as the work role. This disturbance in self-perception may be viewed as a biographical disruption, a perceived alteration in personal normative and historical life patterns.

\section{Coping Difficulties-What Has Been Difficult?}

Responses to this query were similar to the stressors above and included, in the order of frequency, managing pain $(n=18)$, managing complications $(n=13)$, and mobility $(n=13)$. Difficulties with fatigue, feeling weak, and "struggling and having no strength" were also prevalent. Patients expressed some uncertainty regarding illness management, particularly diabetes, and not having questions answered. Themes of "returning to normal" and readjusting to a normal sense of self were prevalent in response to this query as well. Striving to reintegrate oneself as "normal" was interpreted as a need for biographical reconstruction.

8 Miller, Piacentine, \& Weiss 
Because respondents in the low-coping-difficulties group had only one or two responses for the next seven categories (caring for self, managing the medical condition, family, advice needed, calls to MD, ED visits or readmission, and information they wished they had known), qualitative findings for these categories are described as a whole and are not classified within high- and low-difficulty groups.

\section{Coping Difficulties-Caring for Self and Managing the Medical Condition}

Difficulties caring for self focused on mobility issues and performing activities of daily living. Mobility problems varied from getting out of bed and managing the stairs to meeting hygiene needs such as taking a shower (a problem for 9 respondents) or even "bending over." Another general theme emerging was that the time for recovery was not congruent with patients' expectations. "Taking longer to get my strength back" and not being prepared for the fatigue and recovery time were disclosed. These responses reflected self-discouragement and not being able to perform up to previously determined expectations with self-competence threatened. Respondents indicated difficulties with medication management-such as being troubled over side effects and worrying about antibiotics and "blood counts" related to coumadin. Dealing with fatigue and striving to be "normal" emerged again in this category. The respondents' focus on returning to normal emerged again, indicating that their biographies and perceptions of themselves as competent in desired roles had been threatened.

\section{Coping Difficulties-Family}

The fact that family had to take on new roles such as managing household tasks, taking on caregiver roles related to illness management, and transporting the patient was troubling $(n=$ 21). Respondents expressed statements such as, "I was a burden to them and couldn't do anything about it" and "I had to adjust to not being 100\% and accept help from family." Emotional issues included the family's role to "help me from getting depressed as I can't do anything." "This has been stressful for them because they have to 'babysit' me." "Having me be sick is hard psychologically for the family." This new dependency on family was a concern for respondents and is another dimension of changed perception of self.

\section{Coping Difficulties-Advice Needed From Family or Friends}

The most frequent need in contacting family or friends was for emotional support. Patients disclosed they needed "somebody to talk with and get moral support" from. They also needed encouragement to "keep fighting" and to "help me stay positive," reassurance, or just somebody to talk to so as to alleviate loneliness. One respondent solicited prayers from friends. Information was solicited about illness self-care (diabetes) and medications. Help with 
transportation and errands, from groceries to filling prescriptions, was described as needed. Some had family members who were nurses or dieticians who were contacted for more professional assistance. Patients sought input to maintain a positive outlook and reassurance of a return to a "normal" previous self.

\section{Coping Difficulties-Needing to Call the MD, Use Emergency Services, and Readmission}

Contacts with the physician by phone or visit were for routine medication adjustment or postoperative care $(n=38)$. Ten respondents $(9 \%)$ reported problem-focused provider contacts for concerns such as urinary retention, edema, "my breast just did not look right," and bleeding. Four patients used the ED for heart problems, "leg turned purple," respiratory problems, and a broken toe. Two patients had died since hospital discharge, and five were readmitted for pain management, pins inserted into a broken toe, infections, phlebitis, and congestive heart failure. Despite concerns about ongoing fatigue and lack of recovery according to the patient's expectations, contacts to the health care system were for medical issues and did not include seeking reassurance about the recovery process.

\section{What Patients Wished They Had Known}

The things patients came to know postdischarge that they wished they had known predischarge are listed in the following two categories: knowledge about recovery and knowledge about the disease.

Knowledge about recovery ( $n=19$ respondents)

- More information about the recovery process, length of time to recover, time to recover previous energy level, healing time-patients anticipated this time line to be shorter.

- How long to miss work - patients wanted to plan this more precisely and inform employers

- To be prepared for the fatigue level and ongoing feelings of lethargy

- That "I would heal and not have the previous complications"

- Some "inkling of how bad this would be"-pain, immobility, recovery time

- Someone with whom to talk who went through this—getting another's (lay person's) perspective was important

Knowledge about diagnosis, disease, treatment $(n=14)$

- Cause of the problem so as to prevent it in the future-reasons for admission

10 Miller, Piacentine, \& Weiss 
- Information about health status, diabetes, and other prevalent diagnoses

- Opportunity and encouragement to ask more questions about the diagnosis, procedures, what to expect

\section{Core Theme: Biographical Reconstruction}

A prominent posthospitalization challenge was concern about the length of time to recover. Uncertainty about time lines to recovery, regaining functionality, and resuming roles emerged in the context of required dependence on others and worries about returning to normalcy in family and work life. The desire for reconstruction of one's self encompasses these themes and seems to be the core process of dealing with posthospitalization coping challenges. Being "not me" and wanting to return to a level of personal normalcy in physical, functional, and role dimensions constituted the recovery trajectory described by the patients in this study. Reconstruction of the biographical self, of the way one describes one's self, and of relationships with family based on norms of one's past was an overarching theme in the responses to interview questions. The struggles of the postdischarge period reflect the disconnect among the present description or biography of self, the historical biography of self, and the evolving biography as it will emerge in the future. Patients wanted to envision a future with themselves intact, with recovery complete, and with a resumption of life as normal. For some, this return to a former biographical self will be a reality; for others, a different biography will be constructed.

\section{Discussion}

Figure 1 presents a diagrammatic representation of the processes of hospitalization, discharge, and transition to home after discharge with the accompanying biographical disruption and reconstruction. These processes occur over time and are overlapping. Patients face ongoing challenges after hospital discharge to home. These all relate to some degree to a reconstruction of a concept of self, anticipation of role resumption, and obtaining the needed knowledge and competence to manage the health problem. Striving for returning to a normal sense of self was a prevalent theme. This central theme is referred to as biographical reconstruction in that it extended beyond one's physical self and included work roles, family, and an anticipation of a full recovery and return to one's previous self. Despite the hardware in their back, the missing breast, the pancreas that no longer works at full capacity, and the multitude of changes caused and traumas experienced by hospitalization, patients try to assimilate these into their prior or newly constructed concept of self. Chronic illness has been 11 Miller, Piacentine, \& Weiss 
described as biographical disruption (Bury, 1982). Stull, Starling, Haas, and Young (1999) found that people with a new diagnosis of heart failure engaged in a process to reconstruct their identity by eventually reaching acceptance and making a decision to get on with life. As noted in the current study and supported by Rogers, Kennedy, Nelson, and Robinson (2005), this process is not completed during the hospitalization phase, requiring biographical reconstruction to continue after discharge. In identifying the knowledge they would like to have received to help with the transitional period after discharge, this study's respondents desired knowledge about their recovery to empower themselves to create their ongoing biographies and knowledge about their disease process to create new biographical descriptions of their present and future. Put in this context, the importance of discharge teaching cannot be overstated.

Findings from the PDCDS support the qualitative results. Items with higher scores appear to have an emotional need theme (stressful life, difficulty with recovery, emotional support needed, difficulty for family), whereas items with lower difficulty scores have a medical management theme (caring for self, managing medical condition, care for your medical needs). The overall low coping difficulty scores obtained for the 3 weeks after hospital discharge could be influenced by the fact that this was the first hospitalization for only $10 \%$ of this sample. Of the respondents, $90 \%$ had experience with this type of transition in the past, which may have prepared them for posthospitalization challenges.

Although there were no significant differences between people living alone and those who were not alone on the PDCDS, on contacts with the health care system, or readmissions, it is possible that those living alone had social support networks well established with adequate numbers of people to provide needed assistance if called. That is, they may not have been socially isolated. Lysack, MacNeill, and Lichtenberg (2001) suggested that living alone is not a dichotomous variable but rather has degrees to it, affected by support from friends and family as well as environmental variables and people wanting to live alone.

\section{Limitations}

Limitations to this study are recognized. A convenience sample of adult medical-surgical patients was sampled from a single Midwestern hospital. The study reported here is part of a larger study of discharge readiness (Weiss et al., 2007). This attention to discharge readiness may have influenced the depth of patient preparation for transition to home and may have modified postdischarge coping difficulties of this sample. Patient self-report was the sole source of data. Telephone interviewers requested responses to questions with quantitative response sets followed by a query in the form of an open-ended question. This format resulted in brief

\section{Miller, Piacentine, \& Weiss}


responses rather than in-depth interviews. No differences were found based on living status (alone or with others); however, no data were collected about whether people living alone had adequate social support to provide needed assistance. The sample consisted of a broad crosssection of adult medical-surgical patients with a variety of diagnoses. The sample size did not permit analysis of coping difficulties by patient type.

\section{Application}

How nurses interact, having established a therapeutic alliance with patients as full partners in care decisions, is the core component of preparing people to competently face challenges after hospital discharge. Patient centeredness requires that health professionals listen to patients, explore meanings of disruptions in health that have occurred to them, discover patients' perspectives about anticipated ongoing self-management demands, and review patients' goals.

Patients in this study reported overall low levels of difficulty, particularly with self-care and managing their medical condition. These are the typical foci of patient education in preparation for discharge. Patients reported that preparation for the stressful realities and life complexities that compound the recovery process is missing from discharge education (LeClerc et al., 2002). The stresses associated with personal and family disruption and the need for emotional support relate to the overall perception of the posthospitalization period as stressful. The stresses extend beyond medical care issues to being prepared for the time needed for recovery time, as this seemed to threaten their intact perception of self. In addition, patients need to know when to resume important roles. They need to anticipate fatigue, which is prevalent on return home; however, they need reassurance that this is a temporary interruption in their energy state.

Focusing discharge preparation on competence and skill building without attention to confidence building and development of supportive systems necessary to manage biographical disruption and reconstruction ignores the complex reality of the total postdischarge experience. Preparing patients for the posthospitalization period needs to include preparing for role reversals (to be cared for by others), being patient with themselves while contemplating goals to be accomplished, being ready for unanticipated fatigue while wanting to resume work and other roles, managing worries and family disruption, and soliciting and accepting assistance.

Reconstruction of one's biography includes viewing oneself as normal. In other words, patients may be prepared to manage the health problems but are not prepared with how they will feel, what emotions they may experience, and how to temporarily modify their expectations of self

\section{Miller, Piacentine, \& Weiss}


and reorganize their perceptions of self.

Although studies have been conducted about the process of discharge planning (Bowles, Naylor, \& Foust, 2002; Bull et al., 2000; Bull, \& Roberts, 2001), more research is needed to systematically identify needs and concerns of specific populations and developmental age groups after hospitalization. Esche and Tanner (2005) reported that the elderly who have decreased resilience after discharge are those who live alone, are depressed, are older, and have decreased vision. More research is needed with people discharged to home who live alone. Responses about feeling uncertain, particularly with not knowing about illness management, not having questions answered, and not really knowing about how to "manage diabetes," direct professional care providers to assess patient understanding, evaluate health literacy, and plan specific follow-up care. Although patients may initially find senses of relief and joy and a return of a sense of control over going home (Olofsson, Andersson, \& Carlberg, 2005), these feelings of elation are quickly replaced by the realization of care demands and fatigue and an understanding that recovery will take an unpredictable amount of time. Worries about work, family, and being normal mount, and occasionally preventable complications occur. Patients deal with complexities of adjusting to being home, managing health problems, and anticipating recovery while reconstructing their biographical self, the core psychosocial process discovered in this study. Moving from hospital to home is a transition characterized by an initial disruption of one's biographical self. Over time, with successful emotional and physical recovery, reconstruction of one's biography can occur.

\section{References}

American Hospital Association and the Picker Institute. (1997). Eye on patients: Excerpts from a report on patients' concerns and experiences about the health care system. Journal of Healthcare Finance, 23(4), 2-11.

Anthony, M., \& Hudson-Barr, D. (2004). A patient-centered model of care for hospital discharge. Clinical Nursing Research, 13(2), 117-136.

Bezold, C. (2005). A future of patient-centered care: Scenarios, visions, and audacious goals. Journal of alternative and Complementary Medicine, 11(Suppl. 1), S77-S84.

Bowles, K. H., Naylor, M. D., \& Foust, J. B. (2002). Patient characteristics at hospital discharge and a comparison of home care referral decisions. Journal of the American Geriatrics Society, 50, 336-342.

Bull, M., Hansen, H. E., \& Gross, C. (2000). A professional-patient partnership model of

14 Miller, Piacentine, \& Weiss 
discharge planning with elders. Journal of Applied Nursing Research, 13(1), 18-28. Bull, M., \& Jervis, L. L. (1997). Strategies used by chronically ill older women and their caregiving daughters in managing post hospital care. Journal of Advanced Nursing, 25(3), 541-547.

Bull, M., \& Roberts, J. (2001). Components of a proper hospital discharge. Journal of Advanced Nursing, 35(4), 571-581.

Bury, M. (1982). Chronic illness as biographical disruption. Sociology of Health and IIIness, 4, 167-182.

Coleman, E., Parry, C., Chalmers, S., \& Min, S. (2006). The care transitions intervention: Results of a randomized controlled trial. Archives of Internal Medicine, 166, 1822-1828.

Corser, W. (2006). The perceptions of older veterans concerning their post discharge outcome experiences. Applied Nursing Research, 1(2), 63-69.

Crockett, A. J., Cranston, S. M., Moss, J. R., \& Alpers, J. H. (2002). The impact of anxiety, depression and living alone in chronic obstructive pulmonary disease. Quality of Life Research, 111, 309-316.

Cumbie, S., Conley, V., \& Burman, M., (2004). Advanced practice nursing model for comprehensive care with chronic illness: Model for promoting process engagement. Advances in Nursing Science, 3, 70-80.

Esche, C., \& Tanner, E. (2005). Resiliency: A factor to consider when facilitating the transition from hospital to home in older adults. Geriatric Nursing, 26(4), 218-222.

Frasure-Smith, N., Lespérance, F., Gravel, G., Masson, A., Juneau, M., Talajic, M., et al. (2000). Social support, depression, and mortality during the first year after myocardial infarction. Circulation, 101, 1919-1924.

Friedmann, E., Thomas, S. A., Liu, F., Morton, P. G., Chapa, D., \& Gottlieb, S. S. (2006). Relationship of depression, anxiety, and social isolation to chronic heart failure outpatient mortality. American Heart Journal, 152(5), 940.e1-940.e8.

Guzman, J. S., Sohn, L., \& Harada, N. D. (2004). Living alone and outpatient care use by older veterans. Journal of the American Geriatrics Society, 52, 617-622.

Hollingshead, A. (1975). Four factor index of social status (Working paper). New Haven, CT: Hollingshead.

Institute of Medicine. (2001). Crossing the quality chasm. Washington, DC: National Academies Press.

Koelling, T., Johnson, M., Cody, R., \& Aaronson, K. (2005). Discharge education improves

15 Miller, Piacentine, \& Weiss 
clinical outcomes in patients with chronic heart failure. Circulation, 111, 179-185.

Korttila, K. (19991). Anaesthesia for ambulatory surgery: Firm definitions of "home readiness" needed. Annals of Medicine, 23(6), 635-636.

Lauver, D. R., Ward, S. E., Heidrich, S. M., Keller, M., Bowers, B., Brennan, P. F., et al. (2002). Patient centered interventions. Research in Nursing and Health, 25, 246-255.

LeClerc, C. M., Wells, D., Craig, D., \& Wilson, J. L. (2002). Falling short of the mark: Tales of life after hospital discharge. Clinical Nursing Research, 11(3), 242-263.

Lysack, C. L., MacNeill, S. E., \& Lichtenberg, P. A. (2001). The functional performance of elderly urban African-American women who return home to live alone after medical rehabilitation. American Journal of Occupational Therapy, 55(4), 433-440.

Mahoney, J. E., Eisner, J., Havighurst, T., Gray, S., \& Palta, M. (2000). Problems of older adults living alone after hospitalization. Journal of General Internal Medicine, 15, 611-619.

Meleis, A. I., Sawyer, L. M., Im, E.-O., Messias, D. K., Hilfinger, D. K., \& Schumacher, K. (2000). Experiencing transitions: An emerging middle-range theory. Advances in Nursing Science, 23(1), 12-28.

Olofsson, A., Andersson, A., \& Carlberg, B. (2005). "If only I manage to get home I'll get better"-Interviews with stroke patients after emergency stay in hospital on their experiences and needs. Clinical Rehabilitation, 19, 433-440.

Rogers, A., Kennedy, A., Nelson, E., \& Robinson, A. (2005). Uncovering the limits of patientcenteredness: Implementing a self-management trial for chronic illness. Qualitative Health Research, 15(2), 224-239.

Rozanski, A., Blumenthal, J. A., \& Kaplan, J. (1999). Impact of psychological factors on the pathogenesis of cardiovascular disease and implications for therapy. Circulation, 99, 2192-2217.

Stull, D., Starling, R., Haas, G., \& Young, J. (1999). Becoming a patient with heart failure. Heart and Lung, 28(4), 284-292.

Wagner, E., Bennett, S., Austin, B., Greene, S., Schaefer, J., \& Vonkorff, M. (2005). Finding common ground: Patient-centeredness and evidence-based chronic illness care. Journal of Alternative and Complementary Medicine, 11(Suppl. 1), S7-S15.

Weiss, M., \& Piacentine, L. (2006). Psychometric properties of the Readiness for Hospital Discharge Scale. Journal of Nursing Measurement, 14(3), 163-180.

Weiss, M., Piacentine, L., Ancona, J., Gresser, S., Toman, S., \& Vega-Stromberg, T. (2007). Perceived readiness for hospital discharge in adult medical-surgical patients. Clinical

16 Miller, Piacentine, \& Weiss 
Nurse Specialist, 21(1), 31-42.

\section{Notes}

- Judith Fitzgerald Miller, PhD, RN, FAAN, is a professor and dean at the University of Missouri Sinclair School of Nursing.

- Linda B. Piacentine, MS, RN, APRN-BC, is a PhD student at Marquette University College of Nursing.

- Marianne Weiss, DNSc, RN, is an associate professor and the Wheaton Franciscan Healthcare, St. Joseph/Sister Rosalie Klein Professor of Women's Health at Marquette University College of Nursing.

\section{Appendix}

Table 1

Sample

\begin{tabular}{|c|c|c|c|c|c|}
\hline & $M$ & $S D$ & Range & $\%$ & $n$ \\
\hline Age (years) & 54.6 & 14.8 & $23-88$ & & \\
\hline \multicolumn{6}{|l|}{ Race } \\
\hline White & & & & 67.6 & 77 \\
\hline Black & & & & 29.7 & 33 \\
\hline Other & & & & 2.7 & 3 \\
\hline \multicolumn{6}{|l|}{ Gender } \\
\hline Female & & & & 52.2 & 59 \\
\hline Male & & & & 47.8 & 54 \\
\hline \multicolumn{6}{|l|}{ Marital status } \\
\hline Married & & & & 53.1 & 60 \\
\hline Widowed & & & & 14.2 & 16 \\
\hline Single, divorced, separated & & & & 32.7 & 37 \\
\hline Living alone & & & & 20.5 & 23 \\
\hline Surgical & & & & 51.3 & 58 \\
\hline Medical & & & & 48.7 & 55 \\
\hline First time in hospital & & & & 9.9 & 11 \\
\hline Days in hospital & 5.1 & 4.2 & $1-28$ & & \\
\hline Socioeconomic status-Hollingshead (1975; max of 66$)$ & 39.0 & 12.8 & $9-63$ & & \\
\hline \multicolumn{6}{|l|}{ Payer } \\
\hline Medicaid or GAMP & & & & 10.0 & 9 \\
\hline \multicolumn{6}{|l|}{ Education } \\
\hline Less than high school & & & & 14.4 & 16 \\
\hline High school & & & & 54.9 & 61 \\
\hline College graduate & & & & 30.6 & 34 \\
\hline
\end{tabular}

Note: $N=113$. GAMP $=$ General Assistance Medical Program .

17 Miller, Piacentine, \& Weiss 
Table 2

Post-Discharge Coping Difficulty Scale Item Means

\begin{tabular}{|c|c|c|}
\hline Item & $M$ & SD \\
\hline 1. How stressful has your life been? & 4.0 & 2.9 \\
\hline 2. How much difficulty have you had with your recovery? & 3.4 & 3.0 \\
\hline 3. How much difficulty had you had with caring for yourself? & 1.9 & 2.7 \\
\hline 4. How much difficulty had you had managing your medical condition? & 1.8 & 2.8 \\
\hline 5. How difficult has the time been for your family members or other close people? & 2.8 & 2.9 \\
\hline 6. How much help have you needed with caring for yourself? & 2.5 & 2.9 \\
\hline 7. How much emotional support have you needed? & 3.4 & 3.2 \\
\hline 8. How confident have you felt in your ability to care for your own needs? & 2.1 & 2.5 \\
\hline $\begin{array}{l}\text { 9. Have you been able to take care of your medical needs such as medications or } \\
\text { treatments? }\end{array}$ & 0.9 & 1.8 \\
\hline How well have you adjusted to being at home since your hospitalization? ${ }^{\mathrm{a}}$ & 1.1 & 1.9 \\
\hline
\end{tabular}

Note: $N=113$. Item range $=0$ to 10 ; higher scores indicate higher coping difficulty.

a. Question has been reverse scored.

Table 3

Stressors of People With High and Low Coping Difficulty

\begin{tabular}{|c|c|c|c|}
\hline \multirow[b]{2}{*}{ Difficulty } & \multicolumn{2}{|c|}{ Number of Responses } & \multirow[b]{2}{*}{ Examples } \\
\hline & $\begin{array}{l}\text { High PDCDS } \\
(n=56)\end{array}$ & $\begin{array}{c}\text { Low PDCDS } \\
(n=57)\end{array}$ & \\
\hline Pain & 11 & 4 & \\
\hline Recovery challenges & 9 & 6 & $\begin{array}{l}\text { Fever, catheter care, time for } \\
\text { recovery, incongruent with } \\
\text { expectations }\end{array}$ \\
\hline Lack of normalcy & 6 & 6 & $\begin{array}{l}\text { Not being able to do things as before, } \\
\text { trying to get back to normal }\end{array}$ \\
\hline Work issues & 9 & 7 & $\begin{array}{l}\text { Getting back, not being able to work, } \\
\text { getting behind at work }\end{array}$ \\
\hline Mobility issues & 8 & 3 & $\begin{array}{l}\text { Being homebound, stairs, getting into } \\
\text { and out of bed }\end{array}$ \\
\hline Family care & 9 & 0 & $\begin{array}{l}\text { Care for kids, not being there for } \\
\text { husband }\end{array}$ \\
\hline Daily hassles & 5 & 2 & $\begin{array}{l}\text { Little things, car problems, pipe } \\
\text { broke, daily chores, living alone, } \\
\text { everyday life }\end{array}$ \\
\hline Medical follow-up & 3 & 2 & $\begin{array}{l}\text { Readmitted with blood clot, back and } \\
\text { forth because of complications, MD } \\
\text { visits }\end{array}$ \\
\hline
\end{tabular}

Note: $N=113$. PDCDS $=$ Post-Discharge Coping Difficulty Scale.

18 Miller, Piacentine, \& Weiss 
Figure 1

Transition From Hospital to Home-Biographical Reconstruction
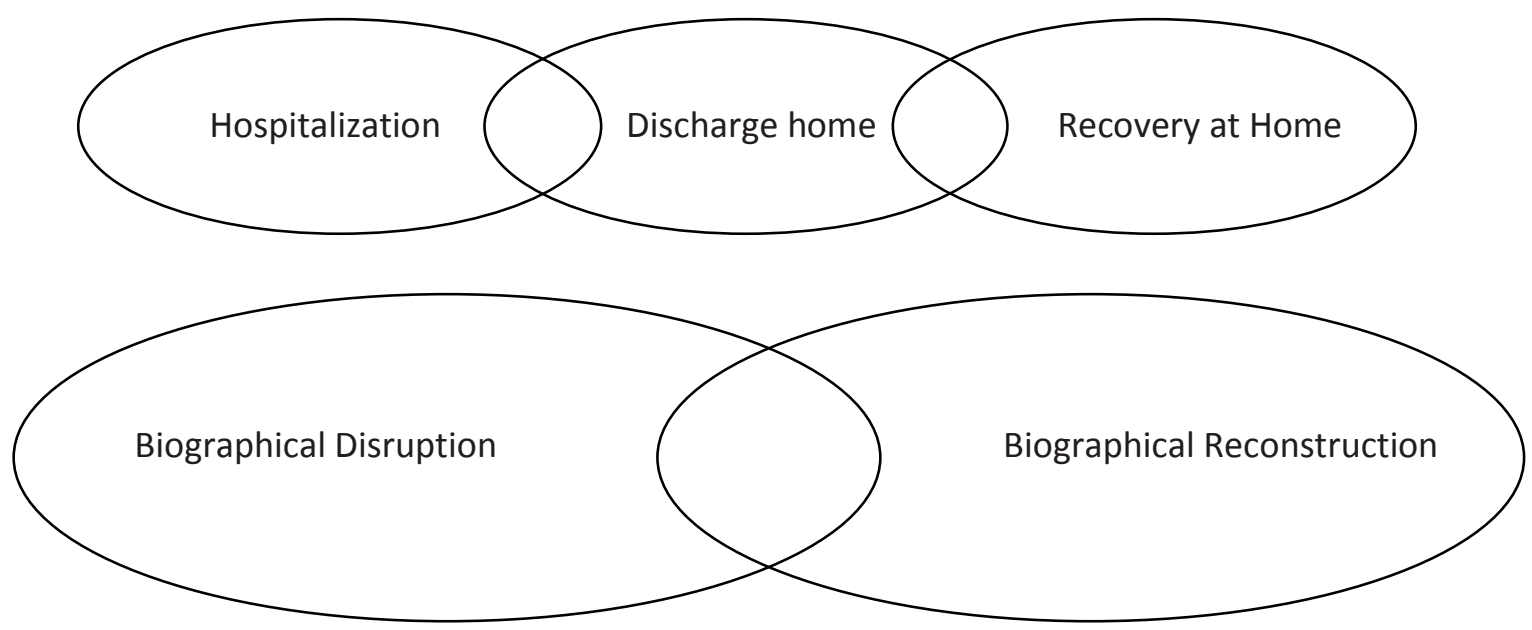

TIME $>>>>>>>>>>>>>>>>>>>>>>>>>>>>$

19 Miller, Piacentine, \& Weiss 